\title{
Short communication: Milk urea nitrogen as a predictor of urinary nitrogen and urea nitrogen excretions of late-lactation dairy cows fed nitrogen-limiting diets
}

\author{
T. Barros, ${ }^{1}$ K. F. Reed, ${ }^{2}$ J. J. Olmos Colmenero, ${ }^{3}$ and M. A. Wattiaux ${ }^{1 *}$ \\ ${ }^{1}$ Department of Dairy Science, University of Wisconsin-Madison, Madison 53706 \\ ${ }^{2}$ USDA-Agricultural Research Service, US Dairy Forage Research Center, Madison, WI 53706 \\ ${ }^{3}$ Departamento de Ciencias Pecuarias y Agrícolas, Centro Universitario de Los Altos de la Universidad de Guadalajara, Tepatitlán, Jalisco, \\ México, 47600
}

\section{ABSTRACT}

Our objectives were to assess the relationships between milk urea $\mathrm{N}(\mathrm{MUN})$, serum urea $\mathrm{N}$ (SUN), urine $\mathrm{N}$ (UN), and urinary urea $\mathrm{N}$ (UUN) in late-lactation cows fed N-limiting diets and compare these relationships with those previously established. Data were from a pen-based study in which 128 Holstein cows had been assigned to 1 of 16 pens in a randomized complete block design to assess the effects of diets containing 16.2, 14.4, 13.1, and $11.8 \%$ crude protein (CP, dry matter basis) during a 12-wk period. At least half of the cows in each pen were randomly selected to collect pen-level samples of serum and urine in wk 3,7 , and 11 , when wk in lactation averaged 35,39 , and 43 , respectively. A mixed model was developed to study the relationship of MUN with SUN, UN, and UUN. Week of lactation did not affect the relation between MUN and SUN across dietary treatments. However, we found a week $\times$ MUN interaction, suggesting that between wk 35 and 43 of lactation, UN excretion decreased from 89 to $73 \mathrm{~g} / \mathrm{d}(-17 \mathrm{~g} / \mathrm{d})$ when MUN was $6.0 \mathrm{mg} / \mathrm{dL}$ ( $11.8 \%$ dietary CP) but increased from 142 to $149 \mathrm{~g} / \mathrm{d}$ $(+7 \mathrm{~g} / \mathrm{d})$ when MUN was $13.3 \mathrm{mg} / \mathrm{dL}(16.2 \%$ dietary CP). These effects were essentially due to changes in UUN excretion, which declined from 54 to $37 \mathrm{~g} / \mathrm{d}(-17$ $\mathrm{g} / \mathrm{d})$ and increased from 112 to $117 \mathrm{~g} / \mathrm{d}(+5 \mathrm{~g} / \mathrm{d})$ when MUN was 6.0 and $13.3 \mathrm{mg} / \mathrm{dL}$, respectively. When MUN was $11.2 \mathrm{mg} / \mathrm{dL}$ (15\% dietary CP), UN and UUN excretions remained constant over time. Based on root mean squared prediction error and the concordance correlation coefficient, these data did not conform to most previously published prediction equations because of both mean and slope biases. The discrepancy could have resulted from difference in study design (cow vs.

Received February 6, 2018.

Accepted October 3, 2018.

*Corresponding author: wattiaux@wisc.edu pen as experimental unit), dietary treatments (energy vs. N-limiting diets), frequency of measurement and duration of adaptation period (single measurement after 1 to 3 wk of adaptation vs. repeated measurements over a 12-wk period), method for determining urine volume (total collection vs. spot sampling), and the assay used to measure MUN. However, our data captured changes in kidney physiology that warrant further studies of long-term renal adaptation to N-limiting diets.

Key words: milk urea nitrogen, urinary nitrogen, kidney, dietary crude protein

\section{Short Communication}

Manure $\mathrm{N}$ from livestock operations is a global concern, in part because of undesirable emission of ammonia and nitrous oxide (Dijkstra et al., 2013; Montes et al., 2013). Of the total $\mathrm{N}$ consumed by a dairy cow in North America, approximately $26 \%$ is secreted in milk, whereas 33 and $35 \%$ are excreted in the urine and feces, respectively (Spek et al., 2013a). Fecal N is bound to complex and stable organic structures and thus is relatively resilient to environmental losses. In contrast, urinary $\mathbf{N}(\mathbf{U N})$, which is made up primarily of urea, is the main source of undesirable emissions. Starting on the barn floors (Aguerre et al., 2010), the mixing of feces with urine promotes the conversion of urinary urea $\mathrm{N}$ (UUN) to ammonia $\mathrm{N}$, with ensuing emission that continues throughout the entire manure management chain (Hou et al., 2015). When excess $\mathrm{N}$ is removed from the diet of lactating cows, daily excretions of UN and UUN can be reduced without penalizing milk protein yield (Colmenero and Broderick, 2006). As a highly water-soluble molecule, urea released into the general circulation by the liver equilibrates rapidly with body fluids, including milk (Gustafsson and Palmquist, 1993), leading to a strong correlation between urea $\mathrm{N}$ concentration in blood and milk (Broderick and Clayton, 1997). Subsequent research has proven MUN to 
be a reliable predictor of UN (Kauffman and St-Pierre, 2001; Kohn et al., 2002; Spek et al., 2013a), UUN (Burgos et al., 2007; Powell et al., 2011; Spek et al., 2013a), and ammonia emission (Burgos et al., 2010). Using a whole-farm model, Powell et al. (2014) suggested that each $1 \mathrm{mg} / \mathrm{dL}$ decrease in MUN (in the range of 16 to $10 \mathrm{mg} / \mathrm{dL}$ ) was associated with a $16.6 \mathrm{~g} / \mathrm{d}$ reduction in UUN and 7 to $12 \%$ reduction in emissions of both ammonia and nitrous oxide, depending on manure management chain. These predictions, however, should not be generalized until the relationship between UUN and MUN has been assessed under a variety of conditions. Except for Kauffman and St-Pierre (2001), who used 2 diets, one lower (13\%, DM basis) and the other higher $(17 \%)$ than considered optimal for dietary CP content, most published models that predict UN and UUN from MUN have been created with data collected from cows fed diets with sufficient or excessive levels of CP (Wattiaux and Karg, 2004; Burgos et al., 2007) or from meta-analyses revealing above-optimal levels of dietary CP (Jonker et al., 1998; Spek et al., 2013a). Although stage of lactation has not been identified as a major influencing factor (Burgos et al., 2007; Spek et al., 2013a), research in rodents and humans has shown a substantial effect of pregnancy on kidney function, renal urea filtration, and sodium and water balances (i.e., urine volume; Cheung and Lafayette, 2013). As highlighted in Kohn et al. (2005), kidney function is central to the relationship between BUN $(\mathrm{mg} / \mathrm{dL}$ ) and UN excretion (g/d) across animal species. In addition, the release of urea in the general circulation by the liver may be altered in the last weeks of lactation as the efficiency of utilization of MP decreases as pregnancy progressively takes priority over milk protein synthesis (NRC, 2001). Our recent study (Barros et al., 2017) suggested that cows responded better than expected when fed MP-deficient diets for $12 \mathrm{wk}$, prompting us to explore in a preliminary study the changes in kidney function as a mechanism to enhance $\mathrm{N}$ recycling when N-limiting diets are fed (Barros and Wattiaux, 2015). Thus, in this study, we hypothesized that the relationships of MUN to serum urea N (SUN), UN, and UUN in late-lactation cows fed N-limiting diets for $12 \mathrm{wk}$ may be unique and differ from previously published reports. Our objectives were to investigate these relationships with a data set collected during the experiment reported in Barros et al. (2017) and to compare the prediction of UN and UUN from MUN from this particular data set with previously established prediction equations.

As described in Barros et al. (2017), 128 Holstein cows (mean $\pm \mathrm{SD}$ ) that were $32 \pm 7$ wk of lactation at the start of the trial were stratified by parity $(2.5 \pm$
1.3 lactations) and days pregnant $(86 \pm 25 \mathrm{~d})$ and then randomly assigned to 1 of 16 pens (experimental units), each including 2 primiparous and 6 multiparous cows. After a 3-wk covariate period, pens were randomly allocated to 1 of 4 diets containing 16.2, 14.4, 13.1, or $11.8 \%$ CP (DM basis) for 12 wk. Diets were offered once a day as TMR (at $0700 \mathrm{~h}$ ) and contained $65 \%$ forage (with almost equal proportion of corn silage and alfalfa silage), $13.5 \%$ high-moisture corn, and a $21.5 \%$ concentrate mix (DM basis). The $\mathrm{CP}$ reduction in the diet was achieved by replacing soybean meal with soy hulls in the concentrate mix. Chemical composition of feed and TMR as well as NRC (2001) predictions of nutrient supplies were presented in Barros et al. (2017). The MP balance averaged $-109,-187,-336$, and $-398 \mathrm{~g} / \mathrm{d}$ for the $16.2,14.4,13.1$, or $11.8 \% \mathrm{CP}$, respectively. For all diets, the supply of MP was predicted to be more limiting than the supply of $\mathrm{NE}_{\mathrm{L}}$. Cows were milked twice a day at 0600 and $1700 \mathrm{~h}$. Details on milk sampling protocol and BW measurements can be found in Barros et al. (2017). In this study, MUN was determined by AgSource Laboratory (Menomonie, WI) using a CombiFoss $6600 \mathrm{FT}+/ \mathrm{FC}$ (Foss Electric, Hillerød, Denmark). Pen values for MUN were calculated from milk samples from all cows in the pen. Blood and urine spot samples were collected in wk 35, 39, and 43 of lactation (wk 3, 7, and 11 of the experimental period) from at least half of the cows in each pen (a subset of 4 cows: 1 primiparous and 3 multiparous). Using evacuated serum tubes, blood samples were collected approximately $4 \mathrm{~h}$ after feeding from the coccygeal vein or artery of cows that had been randomly selected once at the beginning of the trial. Serum was isolated after coagulated blood was centrifuged at $1,000 \times g$ for 15 min at room temperature. Pen-level composite samples were prepared and stored at $-20^{\circ} \mathrm{C}$ until determination of urea $\mathrm{N}$ with a colorimetric assay (Chaney and Marbach, 1962). Mid-stream urine samples were collected after manual stimulation of the region around the vulva $6 \mathrm{~h}$ before and $6 \mathrm{~h}$ after feeding on a subset of 4 cows (1 primiparous and 3 multiparous) randomly selected at each sampling. Samples were acidified immediately by diluting $15 \mathrm{~mL}$ of urine in $60 \mathrm{~mL}$ of 0.072 $\mathrm{N} \mathrm{H}_{2} \mathrm{SO}_{4}$ and stored at $-20^{\circ} \mathrm{C}$ until analysis. Pen-level composite samples were analyzed for total $\mathrm{N}$ with a combustion assay (Leco FP-2000 Nitrogen Analyzer, Leco Instruments Inc., St. Joseph, MI), for urea N with an automated colorimetric assay (Broderick and Clayton, 1997), and for creatinine (Lachat Quik-Chem 8000 FIA, Lachat Instruments, Milwaukee, WI). Excretions of UN and UUN were computed using pen-level concentrations, and estimates of urine volume based on a creatinine excretion of $29 \mathrm{mg} / \mathrm{kg}$ of BW per day 
(Valadares et al., 1999; Tebbe and Weiss, 2018), which has been shown to be independent of DIM (Chizzotti et al., 2008).

Univariate regressions were performed using Microsoft Excel (Microsoft Corp., Redmond, WA) to determine coefficients of determination among MUN, SUN, UN, and UUN excretions. In addition, mixed models were developed to investigate the relationship of MUN with SUN and UUN as lactation progressed: $y_{i j}=\mathbf{X}_{i j}^{T} \boldsymbol{\beta}+\rho_{i}+\varepsilon_{i j}$, where $y_{i j}$ is the observation for the $j$ th sampling week $(j=1$ to 3$)$ from the $i$ th pen $(i=1$ to 16$) ; \mathbf{X}_{i j}^{T}$ is the transpose of the covariate vector; $\boldsymbol{\beta}$ is the vector of parameter estimates; $\rho_{i}$ is the random effect of pen $i$; and $\varepsilon_{i j}$ is the residual error. In the full model the fixed-effect covariate vector included the intercept, MUN, week, and MUN $\times$ week interaction. The full model was progressively built by adding covariates one at a time in the order listed. Models were fit using $\mathrm{R}$ statistical software with the lme4 package using REML estimation (Bates et al., 2013).

Our review of extant UN and UUN prediction equations yielded 6 equations to predict $\mathrm{UN}$ and 5 equations to predict UUN. Two methods were used to evaluate the equations: the root mean squared prediction error (RMSPE) and the concordance correlation coefficient (CCC; Lin, 1989, 2000). The RMSPE provides a mea- sure of error in the units of the predicted value and as a percentage of the mean observed value. The RMSPE was calculated as follows:

$$
\operatorname{RMSPE}=\left[(\mathbf{y}-\mathbf{X} \hat{\boldsymbol{\beta}})^{T}(\mathbf{y}-\mathbf{X} \hat{\boldsymbol{\beta}}) n^{-1}\right]^{\frac{1}{2}},
$$

where $\mathbf{y}$ is the vector of observations; $\mathbf{X}$ is the matrix of explanatory variables; $\hat{\boldsymbol{\beta}}$ is the vector of fixed-effect parameter estimates; $n$ is the number of observations in the study $(\mathrm{n}=48)$; and the superscript $T$ denotes the transpose function. The RMSPE was decomposed into the error of central tendency, the error due to regression, and the error of dispersion as described by Bibby and Toutenburg (1977). The CCC combines measures of both precision and accuracy to determine how far the observed data deviate from the line of perfect concordance (a line at $45^{\circ}$ on a square scatter plot), with values close to 1 indicating agreement between observed and predicted (Lin, 1989, 2000). The CCC was calculated using the epi.ccc function in the epiR package (Stevenson et al., 2014) in $\mathrm{R}$ statistical software ( $\mathrm{R}$ Core Group, Vienna, Austria).

For our data set MUN explained $65 \%$ of the variation in SUN, and the regression slope (0.746; Table 1) was intermediate between the values of 0.62 and 0.89

Table 1. Parameter estimates (SE in parentheses) of multiple linear mixed model regression of serum urea N (SUN, mg/dL), urinary N (UN, $\mathrm{g} / \mathrm{d})$, and urinary urea N (UUN, g/d) from MUN $(\mathrm{mg} / \mathrm{dL})$, week of lactation, and MUN $\times$ week of lactation interaction

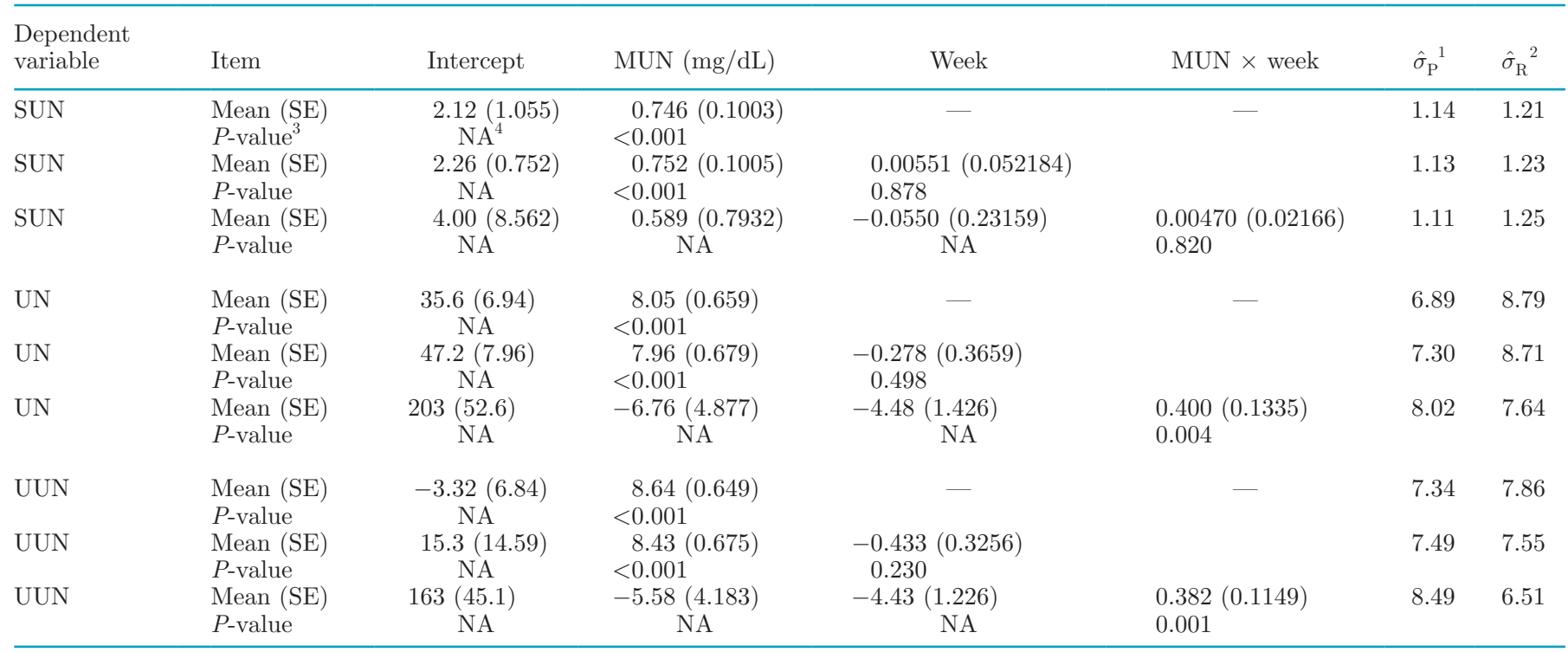

${ }^{1}$ Estimates of the random error due to the pen.

${ }^{2}$ Estimate of the residual random error.

${ }^{3} P$-value between the null (simpler) and alternate model (null model with stepwise addition of MUN, week, and MUN $\times$ week interaction) estimated from chi-squared distribution of likelihood ratio test.

${ }^{4}$ Not applicable. 
mg/dL reported by Broderick and Clayton (1997) and Kauffman and St-Pierre (2001), respectively. Also, in our data set, dietary CP level and MUN explained 77 and $80 \%$ of the variation in UN, respectively. These values agreed closely with the corresponding 72 and $79 \%$ reported in Spek et al. (2013a). However, the regression slope of $8.05 \mathrm{~g}$ of UN/d per unit of MUN found in this study (Table 1) was 68 and $49 \%$ of the values reported in Jonker et al. (1998) and Kauffman and St-Pierre (2001), respectively. These latter authors have shown that UN prediction from MUN can be improved by accounting for variation in BW (Jersey vs. Holstein). Our results indicated only a marginal improvement in a model with MUN adjusted for BW, most likely due to small differences in BW among the Holsteins in the study. In agreement with Colmenero and Broderick (2006), UUN in our study comprised a decreasing percentage of UN with decreasing dietary CP: 81,74 , 68 , and $54 \%$ for dietary CP of $16.2,14.4,13.1$, and $11.8 \%$, respectively. Also, dietary $\mathrm{CP}$ level and MUN explained 80 and $88 \%$ of the variation in UUN, respectively. However, the regression slope between MUN and UUN (8.64 g of UUN/d per unit of MUN; Table 1) was 43 and $35 \%$ smaller than the slopes reported in Powell et al. (2011) and Spek et al. (2013a), respectively.

Results of the mixed model analysis are shown in Table 1. In predicting SUN, neither the week nor the MUN $\times$ week interaction were significant, indicating that the relationship between MUN and SUN was independent of week of lactation covered in our data set. In contrast, for the models that predicted UN and UUN from MUN, the week effect alone was not significant, but the MUN $\times$ week interaction was significant $(P$ $<0.01$ ). This finding highlighted the necessity of including the interaction term to predict both UN and UUN in our data set. Using our data to derive dietary CP from MUN ( $\left.\mathrm{y}=8.25+0.601 \mathrm{x} ; \mathrm{R}^{2}=0.999\right)$ and the models presented in Table 1, MUN of $11.2 \mathrm{mg} / \mathrm{dL}$ corresponded to a diet of $15 \% \mathrm{CP}$, which resulted in excretions of $127 \mathrm{~g} / \mathrm{d}$ for UN and $95 \mathrm{~g} / \mathrm{d}$ of UUN that remained independent of week of lactation. However, for MUN $>11.2 \mathrm{mg} / \mathrm{dL}$ (dietary $\mathrm{CP}>15 \%$ ), UN and UUN excretions were predicted to increase as lactation progressed. For example, when MUN was $13.3 \mathrm{mg} / \mathrm{dL}$ (16.2\% of dietary CP), UN was predicted to increase from 142 to $149 \mathrm{~g} / \mathrm{d}(+7 \mathrm{~g} / \mathrm{d})$ and UUN was predicted to increase from 112 to $117 \mathrm{~g} / \mathrm{d}(+5 \mathrm{~g} / \mathrm{d})$ between wk 35 and 43 of lactation. Conversely, for MUN $<11.2 \mathrm{mg} /$ dL (dietary $\mathrm{CP}<15 \%$ ), UN and UUN excretions were predicted to decrease between wk 35 and 43 of lactation. For example, when MUN was $6.0 \mathrm{mg} / \mathrm{dL}(11.8 \%$ dietary (P), UN was predicted to decrease from 89 to $73 \mathrm{~g} / \mathrm{d}(-17 \mathrm{~g} / \mathrm{d})$ and UUN was predicted to decrease from 54 to $37 \mathrm{~g} / \mathrm{d}(-17 \mathrm{~g} / \mathrm{d})$ between wk 35 and 43

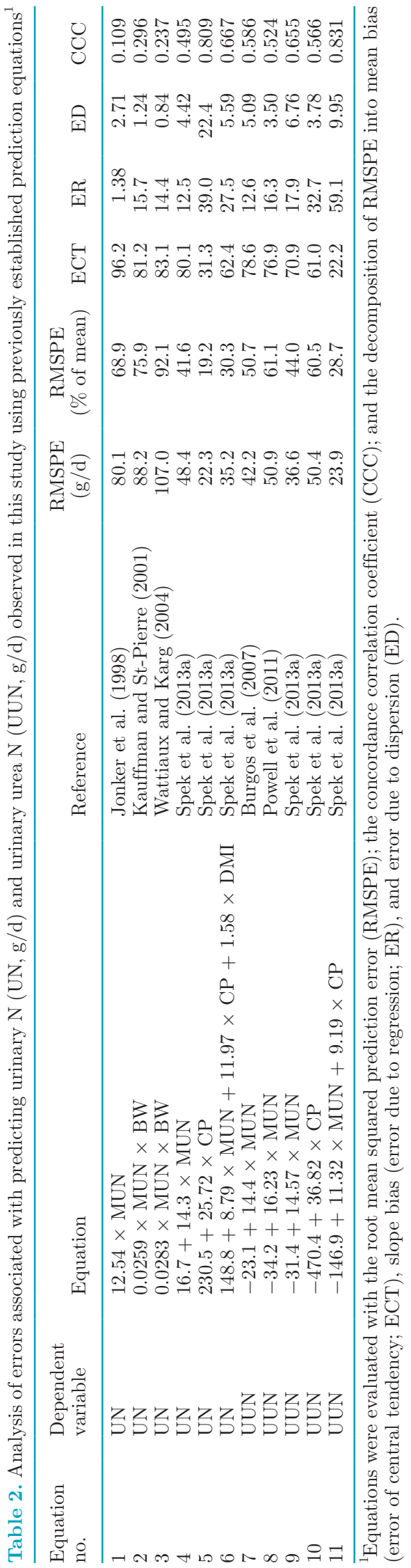


of lactation. In contrast to these results, DIM $(129 \pm$ 58.9 ) was not a significant explanatory factor for UN or UUN in the meta-analysis of Spek et al. (2013a), and stage of lactation (early, mid, and late) had no effect on MUN, plasma urea N, or UUN in the study of Burgos et al. (2007). The former and latter studies predicted 114 and $121 \mathrm{~g} / \mathrm{d}$ of UUN at any point of the lactation for MUN of $10 \mathrm{mg} / \mathrm{dL}$, but for our data set, the same MUN value predicted 86,83 , and $81 \mathrm{~g} / \mathrm{d}$ of UUN for wk 35,39 , and 43 of lactation, respectively.

The analysis of errors (RMSPE and CCC) associated with predicting our observed UN and UUN values using previously established prediction equations is presented in Table 2 and Figure 1. Models that predicted UN excretion showed an RMSPE ranging from 22.3 to $107.0 \mathrm{~g} / \mathrm{d}$ (19.2 to $92.1 \%$ of the mean). All models exhibited high mean bias $(>31 \%$ of the total error) and slope bias [except for the model of Jonker et al. (1998), equation 1 in Table 2]. Similarly, models that predict UUN excretion showed RMSPE ranging from 22.9 to $50.9 \mathrm{~g} / \mathrm{d}$ ( 28.7 to $61.1 \%$ of the mean). All the UUN prediction models showed large mean and slope bias beyond acceptable according to the guidelines by Reed et al. (2015). We believe that our data set did not conform with current models for several possible reasons associated with experimental design and protocol as well as cow biology. First, our excretion data were estimated from spot sampling rather than measured by total urine collection. Working with a group of 18 cows, Tebbe and Weiss (2018) concluded that average urine output did not differ between the 2 methods despite marked difference for some individual cows. Because the data analyzed in our study were pen-based averages, the residual random error of our prediction models
A
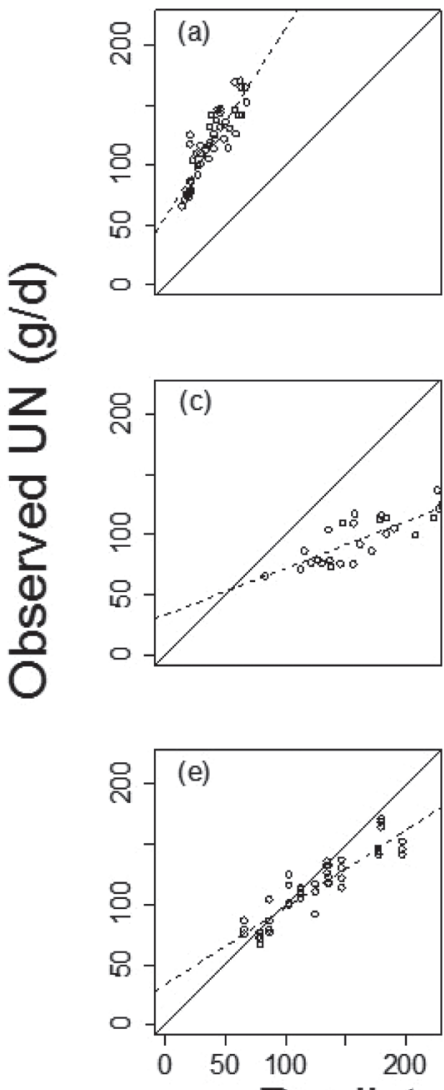

Predicted UN (g/d)
B
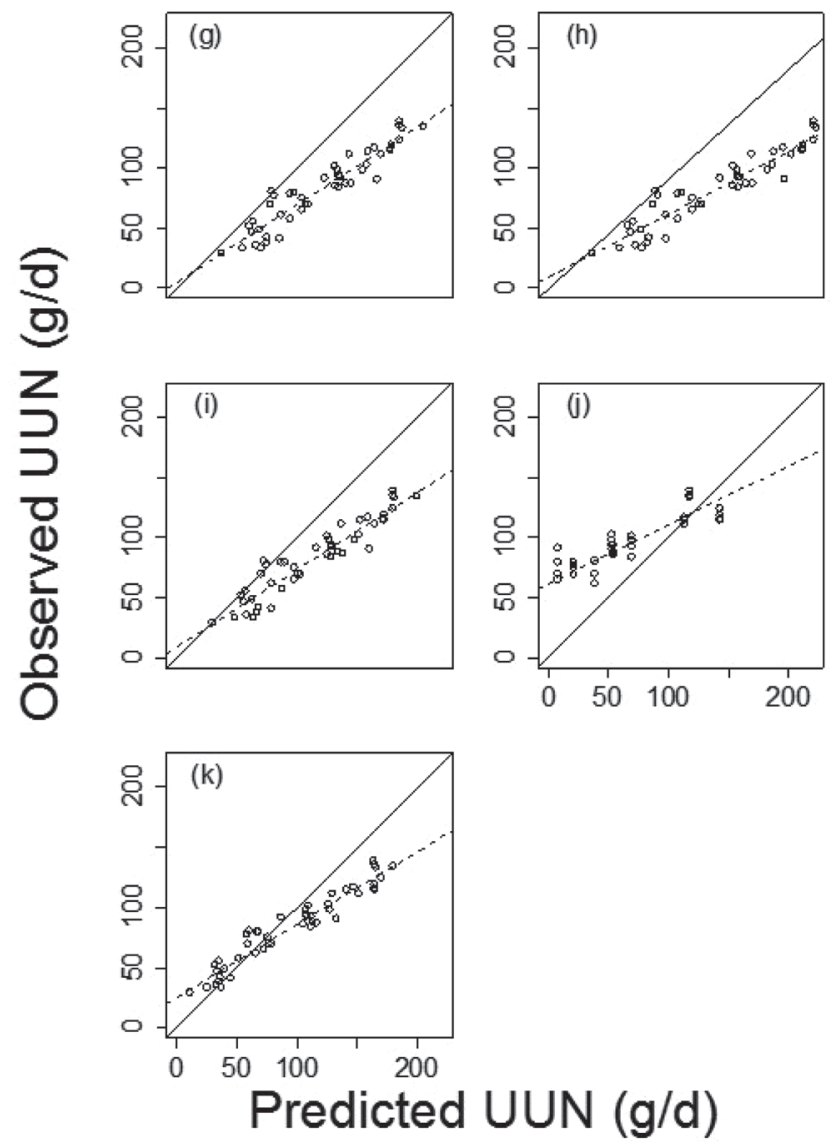

Figure 1. (A) Observed urine $\mathrm{N}(\mathrm{UN})$ versus predicted UN excretion using 6 published equations: (a) Jonker et al. (1998), UN $=12.54 \times$ MUN; (b) Kauffman and St-Pierre (2001), UN = $0.0259 \times$ MUN $\times$ BW; (c) Wattiaux and Karg (2004), UN = $0.0283 \times$ MUN $\times$ BW; (d) Spek et al. (2013a), UN = $16.7+14.3 \times$ MUN; (e) Spek et al. $(2013 \mathrm{a}), \mathrm{UN}=230.5+25.72 \times \mathrm{CP}$; (f) Spek et al. $(2013 \mathrm{a}), 148.8+8.79 \times \mathrm{MUN}+$ $11.97 \times \mathrm{CP}+1.58 \times$ DMI. (B) Observed urinary urea N (UUN) versus predicted UUN excretion using 5 published equations: $(\mathrm{g})$ Burgos et al. (2007), UUN $=-23.1+14.4 \times$ MUN; (h) Powell et al. (2011), UUN $=-34.2+16.23 \times$ MUN; (i) Spek et al. (2013a), UUN $=-31.4+$ $14.57 \times$ MUN; $(j)$ Spek et al. $(2013 a)$, UUN $=-470.4+36.82 \times \mathrm{CP} ;(\mathrm{k})$ Spek et al. $(2013 \mathrm{a}), \mathrm{UUN}=-146.9+11.32 \times$ MUN $+9.19 \times \mathrm{CP}$. 
was reduced when compared with data from individual animals; thus, the total prediction error will be smaller than individual animal data but the systematic biases will represent a larger portion of the remaining error. Care should be taken when interpreting the error decomposition as the systematic biases are expected to appear larger than a similar analysis with individual animal data. Second, cows in our study were at a much later stage of lactation than in previous studies. Week of lactation in our study averaged 39 but was 22.3, 12.0, and 18.4 in Kauffman and St-Pierre (2001), Wattiaux and Karg (2004), and Spek et al. (2013a), respectively. In the work of Burgos et al. (2007), average week of lactation for early-, mid-, and late-lactation cows was 18,25 , and 32 , respectively. Third, in our study diets were $\mathrm{N}$ limiting. Except for the study of Kauffman and St-Pierre (2001), which included a dietary treatment with $13 \% \mathrm{CP}$, most other studies from which prediction equations have been created used levels of dietary $\mathrm{CP}$ that supplied an adequate to excessive amount of N. For example, dietary CP was $16.4,16.6,17.8$, and $18.0 \%$ in Wattiaux and Karg (2004) and 15, 17, 19, and 21\% in Burgos et al. (2007). Similarly, the North American data set of the meta-analysis of Spek et al. (2013a) included 118 treatment means with $17.1 \pm 1.8 \% \mathrm{CP}$. Fourth, in our study, measurements were repeated on cows that remained on the same dietary treatment for up to 12 wk compared with a single measurement performed after 1 to 3 wk of adaptation in most other studies cited here. Fifth, the variability in MUN obtained from different assays (Broderick, 2003) or equipment (Peterson et al., 2004) may also be a source of betweenstudies variation. Nevertheless, under our experimental conditions, we may have captured changes in renal functions due to long-term exposure to distinct levels of dietary $\mathrm{CP}$, with changes in UUN excretion explaining the changes in UN excretion. In their review of factors affecting the MUN:UN ratio, Spek et al. (2013b) concluded that both dietary $\mathrm{CP}$ and physiological state of the animal influence the amount of urea reabsorption that occurs in the kidney (see also Burgos et al., 2007). Alteration of urea reuptake by the kidneys might provide a physiological basis of the significant effect of MUN by week of lactation in predicting UN and UUN from MUN observed in this study. Because UUN is easily lost to the environment, inaccuracies in UUN predictions may lead to inaccuracies in estimates of $\mathrm{N}$ loss from the farm and related environmental impacts. Thus, we hope that our findings will stimulate further research in methods for measuring or predicting urine volume, UN, and UUN under a wide range of experimental conditions and in the mechanisms that govern changes in kidney reabsorption of urea throughout the lactation and reproduction cycle of dairy cows.

\section{ACKNOWLEDGMENTS}

Partial funding was from USDA (Washington, DC) Hatch formula fund no. WIS01725 and WIS01660. The authors thank Sandy Trower and the staff at the University of Wisconsin-Madison Blaine Dairy Cattle Center for animal care, Sandy Bertics (University of Wisconsin-Madison, Dairy Science Department) for guidance in the laboratory, and the anonymous reviewers who helped improve the quality of this publication. Mention of any trademark or proprietary product in this paper does not constitute a guarantee or warranty of the product by the USDA or the Agricultural Research Service and does not imply its approval to the exclusion of other products that also may be suitable.

\section{REFERENCES}

Aguerre, M. J., M. A. Wattiaux, and B. R. Larget. 2010. Effect of dietary crude protein on ammonia- $\mathrm{N}$ emission measured by herd nitrogen mass balance in a freestall dairy barn managed under farm-like conditions. Animal 4:1390-1400. https://doi.org/10 $.1017 /$ S1751731110000248.

Barros, T., M. A. Quaassdorff, M. A. Aguerre, J. J. Olmos Colmenero, S. J. Bertics, and M. A. Wattiaux. 2017. Effects of dietary crude protein concentration on late-lactation dairy cow performance and indicators of nitrogen utilization. J. Dairy Sci. 100:5434-5448. https://doi.org/10.3168/jds.2016-11917.

Barros, T., and M. A. Wattiaux. 2015. Milk urea nitrogen as a predictor of urinary nitrogen excretion in late lactation dairy cows fed four levels of dietary crude protein. J. Dairy Sci. 98(Suppl. 2):755. (Abstr.)

Bates, D., M. Maechler, B. Bolker, and S. Walker. 2013. lme4: Linear mixed-effects models using Eigen and S4. R package version 1.0-5. Accessed Mar. 15, 2017. http://cran.r-project.org/web/packages/ lme4/index.html.

Bibby, J., and H. Toutenburg. 1977. Prediction and Improved Estimation in Linear Models. Wiley, London, UK.

Broderick, G. A. 2003. Effects of varying dietary protein and energy levels on the production of lactating dairy cows. J. Dairy Sci. 86:1370-1381. https://doi.org/10.3168/jds.S0022-0302(03)73721 -7 .

Broderick, G. A., and M. K. Clayton. 1997. A statistical evaluation of animal and nutritional factors influencing concentrations of milk urea nitrogen. J. Dairy Sci. 80:2964-2971. https://doi.org/10 $.3168 / j d s . S 0022-0302(97) 76262-3$.

Burgos, S. A., N. M. Embertson, Y. Zhao, F. M. Mitloehner, E. J. DePeters, and J. G. Fadel. 2010. Prediction of ammonia emission from dairy cattle manure based on milk urea nitrogen: Relation of milk urea nitrogen to ammonia emissions. J. Dairy Sci. 93:23772386. https://doi.org/10.3168/jds.2009-2415.

Burgos, S. A., J. G. Fadel, and E. J. DePeters. 2007. Prediction of ammonia emission from dairy cattle manure based on milk urea nitrogen: Relation of milk urea nitrogen to urine urea nitrogen excretion. J. Dairy Sci. 90:5499-5508. https://doi.org/10.3168/jds .2007-0299.

Chaney, A. L., and E. P. Marbach. 1962. Modified reagents for determination of urea and ammonia. Clin. Chem. 8:130-132.

Cheung, K. L., and R. A. Lafayette. 2013. Renal physiology of pregnancy. Adv. Chronic Kidney Dis. 20:209-214. https://doi.org/10 .1053/j.ackd.2013.01.012.

Chizzotti, M. L., S. C. Valadares Filho, R. F. Diniz Valadares, F H. Martins Chizzotti, and L. O. Tedeschi. 2008. Determination of creatinine excretion and evaluation of spot urine sampling in Holstein cattle. Livest. Sci. 113:218-225. https://doi.org/10.1016/ j.livsci.2007.03.013. 
Dijkstra, J., O. Oenema, J. W. van Groenigen, J. W. Spek, A. M. van Vuuren, and A. Bannink. 2013. Diet effects on urine composition of cattle and $\mathrm{N}_{2} \mathrm{O}$ emissions. Animal 7:292-302. https://doi.org/10 $.1017 / \mathrm{S} 1751731113000578$.

Gustafsson, A. H., and D. L. Palmquist. 1993. Diurnal variation of rumen ammonia, serum urea, and milk urea in dairy cows at high and low yields. J. Dairy Sci. 76:475-484. https://doi.org/10.3168/ jds.S0022-0302(93)77368-3.

Hou, Y., G. L. Velthof, and O. Oenema. 2015. Mitigation of ammonia, nitrous oxide and methane emissions from manure management chains: A meta-analysis and integrated assessment. Glob. Chang. Biol. 21:1293-1312. https://doi.org/10.1111/gcb.12767.

Jonker, J. S., R. A. Kohn, and R. A. Erdman. 1998. Using milk urea nitrogen to predict nitrogen excretion and utilization efficiency in lactating dairy cows. J. Dairy Sci. 81:2681-2692. https://doi.org/ 10.3168/jds.S0022-0302(98)75825-4.

Kauffman, A. J., and N. R. St-Pierre. 2001. The relationship of milk urea nitrogen to urine nitrogen excretion in Holstein and Jersey cows. J. Dairy Sci. 84:2284-2294. https://doi.org/10.3168/jds S0022-0302(01)74675-9.

Kohn, R. A., M. M. Dinneen, and E. Russek-Cohen. 2005. Using blood urea nitrogen to predict nitrogen excretion and efficiency of nitrogen utilization in cattle, sheep, goats, horses, pigs, and rats. J. Anim. Sci. 83:879-889. https://doi.org/10.2527/2005.834879x.

Kohn, R. A., K. F. Kalscheur, and E. Russek-Cohen. 2002. Evaluation of models to estimate urinary nitrogen and expected milk urea nitrogen. J. Dairy Sci. 85:227-233. https://doi.org/10.3168/ jds.S0022-0302(02)74071-X.

Lin, L. I. 1989. A concordance correlation coefficient to evaluate reproducibility. Biometrics 45:255-268. https://doi.org/10.2307/ 2532051.

Lin, L. 2000. Correction: A note on the concordance correlation coefficient. Biometrics 56:324-325.

Montes, F., R. Meinen, C. Dell, A. Rotz, A. N. Hristov, J. Oh, G. Waghorn, P. G. Gerber, B. Henderson, H. P. S. Makkar, and J. Dijkstra. 2013. Special topics - Mitigation of methane and nitrous oxide emissions from animal operations: II. A review of manure management mitigation options. J. Anim. Sci. 91:5070-5094. https://doi .org/10.2527/jas.2013-6584.

NRC. 2001. Nutrient Requirements of Dairy Cattle. 7th ed. Natl. Acad. Press, Washington, DC

Colmenero, J. J., and G. A. Broderick. 2006. Effect of dietary crude protein concentration on milk production and nitrogen utilization in lactating dairy cows. J. Dairy Sci. 89:1704-1712. https://doi .org/10.3168/jds.S0022-0302(06)72238-X.
Peterson, A. B., K. R. French, E. Russek-Cohen, and R. A. Kohn. 2004. Comparison of analytical methods and the influence of milk components on milk urea nitrogen recovery. J. Dairy Sci. 87:17471750. https://doi.org/10.3168/jds.S0022-0302(04)73329-9.

Powell, J. M., C. A. Rotz, and M. A. Wattiaux. 2014. Potential use of milk urea nitrogen to abate atmospheric nitrogen emissions from Wisconsin dairy farms. J. Environ. Qual. 43:1169-1175. https:// doi.org/10.2134/jeq2013.09.0375.

Powell, J. M., M. A. Wattiaux, and G. A. Broderick. 2011. Short communication: Evaluation of milk urea nitrogen as a management tool to reduce ammonia emissions from dairy farms. J. Dairy Sci. 94:4690-4694. https://doi.org/10.3168/jds.2011-4476.

Reed, K. F., D. P. Casper, J. France, and E. Kebreab. 2015. Prediction of nitrogen efficiency in dairy: A review. CAB Rev. 10. https://doi .org/10.1079/PAVSNNR201510001.

Spek, J. W., J. Dijkstra, G. van Duinkerken, W. H. Hendriks, and A. Bannink. 2013a. Prediction of urinary nitrogen and urinary urea nitrogen excretion by lactating dairy cattle in northwestern Europe and North America: A meta-analysis. J. Dairy Sci. 96:43104322. https://doi.org/10.3168/jds.2012-6265.

Spek, J. W., J. Dijkstra, G. van Duinkerken, W. H. Hendriks, and A. Bannink. 2013b. A review of factors influencing milk urea concentration and its relationship with urinary urea excretion in lactating dairy cattle. J. Agric. Sci. 151:407-423. https://doi.org/10.1017/ S0021859612000561.

Stevenson, M., T. Nunes, C. Heuer, J. Marshall, J. Sanchez, R. Thornton, J. Reiczigel, J. Robison-Cox, P. Sebastiani, P. Solymos, and K. Yoshida. 2014. epiR: An R package for the analysis of epidemiological data. $\mathrm{R}$ package version 0.9-57. Accessed Feb. 28, 2017. http://CRAN.R-project.org/package=epiR

Tebbe, A. W., and W. P. Weiss. 2018. Evaluation of creatinine as a urine marker and factors affecting urinary excretion of magnesium by dairy cows. J. Dairy Sci. 101:5020-5032. https://doi.org/ $10.3168 /$ jds.2017-14098

Valadares, R. F. D., G. A. Broderick, S. C. V. Filho, and M. K. Clayton. 1999. Effect of replacing alfalfa silage with high moisture corn on ruminal protein synthesis estimated from excretion of total purine derivatives. J. Dairy Sci. 82:2686-2696. https://doi.org/10 .3168/jds.S0022-0302(99)75525-6.

Wattiaux, M. A., and K. L. Karg. 2004. Protein level for alfalfa and corn silage-based diets: II. Nitrogen balance and manure characteristics. J. Dairy Sci. 87:3492-3502. https://doi.org/10.3168/jds .S0022-0302(04)73484-0. 